\title{
Bilateral hearing loss as a manifestation of neuromyelitis optica
}

Figure 1 Brainstem auditory evoked potentials at presentation
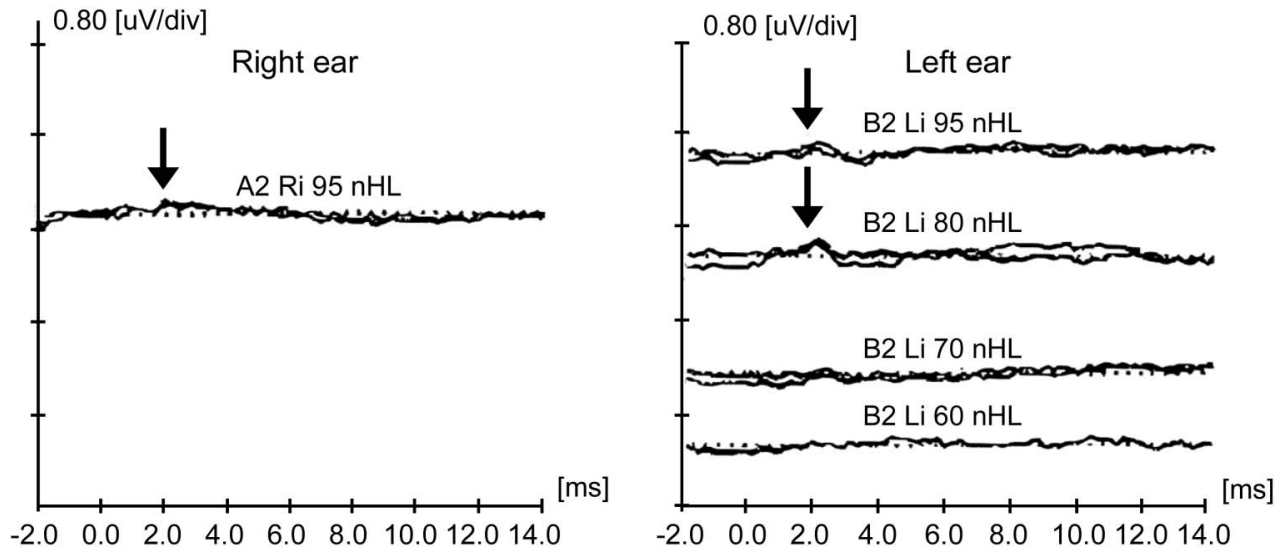

Brainstem auditory evoked potentials performed in both ears at the time of presentation show the bilateral presence of wave I (arrows) and the absence of all subsequent waveforms. These findings are consistent with lesions between the proximal cochlear nerves and the superior olivary nuclei. This is worse on the right, correlating with the MRI findings in figure 2.

Figure $2 \quad$ MRI scans at presentation

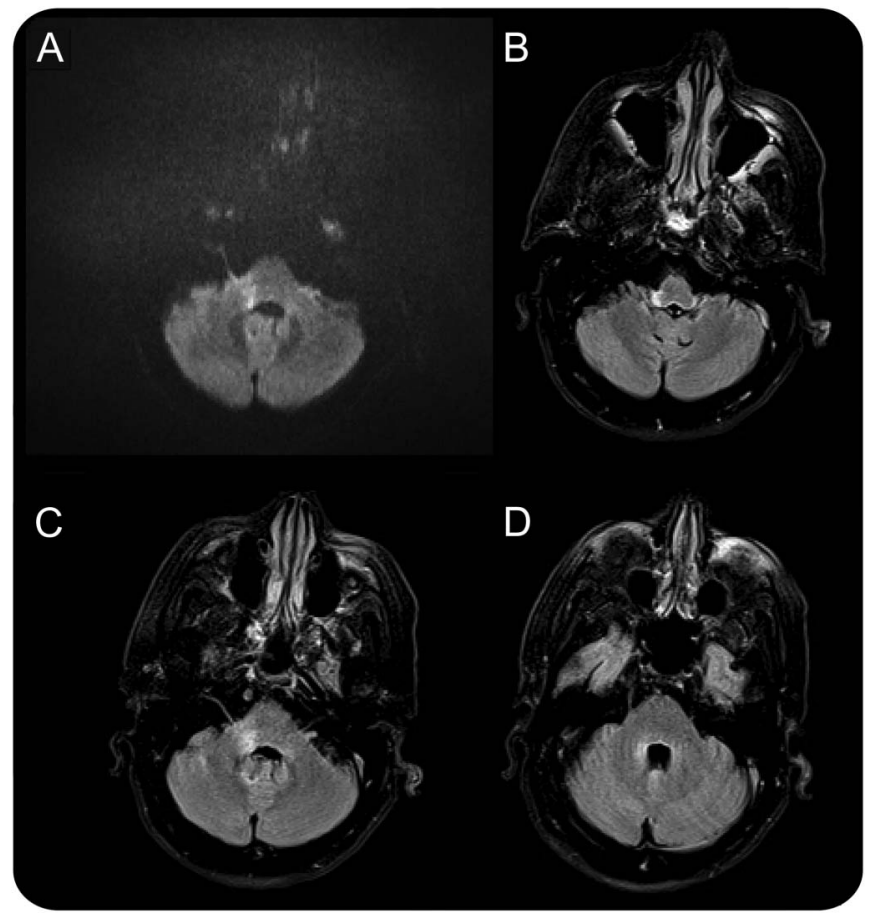

Axial diffusion-weighted imaging (A) and fluid-attenuated inversion recovery (B-D) MRI at the time of presentation show restricted diffusion and T2 hyperintensity in the bilateral inferior cerebellar peduncles as well as in the right middle cerebellar peduncle. These changes are in the region of the cochlear nuclei, which are located near the fourth ventricle and inferior cerebellar peduncles. Dysfunction at this level of the auditory pathway is the likely explanation of this patient's hearing loss. 
A 54-year-old woman with definite neuromyelitis optica (NMO) presented with bilateral hearing loss that progressed to complete deafness over 2 days. Otoscopy, tympanometry, otoacoustic emission testing, and brainstem auditory evoked potentials (figure 1) were consistent with central lesions bilaterally. MRI showed T2 hyperintensities and restricted diffusion near the cochlear nuclei, more prominent on the right (figure 2). Hearing loss resolved after administration of IV methylprednisolone followed by plasmapheresis. The cochlear nuclei are located in the dorsal medulla, adjacent to the fourth ventricle. Such periventricular regions highly express aquaporin- 4 and have been implicated as sites of brain involvement in NMO., ${ }^{1,2}$

Sean Gratton, MD, Faria Amjad, MD, Forough Ghavami, DO, Benjamin Osborne, MD, Carlo Tornatore, MD, Carlos Mora, MD

From Medstar Georgetown University Hospital Department of Neurology, Washington, DC.

Author contributions: Drs. Gratton, Amjad, and Ghavami: study concept, collecting data, and writing the manuscript. Drs. Osborne, Tornatore, and Mora: study concept and editing the manuscript.

Study funding: No targeted funding reported.

Disclosure: S. Gratton, F. Amjad, and F. Ghavami report no disclosures relevant to the manuscript. B. Osborne is on the speaker's bureau for Teva and Biogen Idec. C. Tornatore has received honoraria from Biogen Idec, Novartis, and Genzyme. C. Mora reports no disclosures relevant to the manuscript. Go to Neurology.org for full disclosures.

Correspondence to Dr. Gratton: seangratton@gmail.com

1. Pittock SJ, Weinshenker BG, Lucchinetti CF, et al. Neuromyelitis optica brain lesions localized at sites of high aquaporin 4 expression. Arch Neurol 2006;63:964-968.

2. Popescu BF, Lennon VA, Parisi JE, et al. Neuromyelitis optica unique area postrema lesions: nausea, vomiting, and pathogenic implications. Neurology 2011;76:1229-1237.

\section{Free Michael J. Fox DVD, Video on Parkinson's Disease}

The AAN and the American Brain Foundation present actor and Parkinson's disease patient Michael J. Fox hosting Parkinson's Disease: A Guide for Patients and Families. This new patient education video is now available free to members and the public, either on DVD or online. The free DVD can be ordered while supplies last by visiting AAN.com/view/PatientEducationVideos or calling (800) 879-1960. The video can be viewed online at YouTube.com/AANChannel with other patient education DVDs produced by the AAN.

\section{The Premier Event for the Latest Research on Concussion}

Registration is now open for The Sports Concussion Conference-the premier event on sports concussion from the American Academy of Neurology—set for July 11 through 13, 2014, at the Sheraton Chicago Hotel \& Towers in Chicago. You won't want to miss this one-of-a-kind opportunity to learn the very latest scientific advances in diagnosing and treating sports concussion, postconcussion syndrome, chronic neurocognitive impairment, and controversies around gender issues and second impact syndrome from the world's leading experts on sports concussion. Early registration ends June 9, 2014. Register today at AAN.com/view/ConcussionConference. 


\section{Neurology}

\section{Bilateral hearing loss as a manifestation of neuromyelitis optica}

Sean Gratton, Faria Amjad, Forough Ghavami, et al.

Neurology 2014;82;2145-2146

DOI 10.1212/WNL.0000000000000489

\section{This information is current as of June 9, 2014}

\section{Updated Information \& Services}

References

Subspecialty Collections

Permissions \& Licensing

Reprints including high resolution figures, can be found at: http://n.neurology.org/content/82/23/2145.full

This article cites 2 articles, 1 of which you can access for free at: http://n.neurology.org/content/82/23/2145.full\#ref-list-1

This article, along with others on similar topics, appears in the following collection(s):

Audition

http://n.neurology.org/cgi/collection/audition

Devic's syndrome

http://n.neurology.org/cgi/collection/devics_syndrome

Evoked Potentials/Auditory

http://n.neurology.org/cgi/collection/evoked_potentials-auditory

Information about reproducing this article in parts (figures,tables) or in its entirety can be found online at:

http://www.neurology.org/about/about_the_journal\#permissions

Information about ordering reprints can be found online:

http://n.neurology.org/subscribers/advertise

Neurology ${ }^{\circledR}$ is the official journal of the American Academy of Neurology. Published continuously since 1951, it is now a weekly with 48 issues per year. Copyright (O) 2014 American Academy of Neurology. All rights reserved. Print ISSN: 0028-3878. Online ISSN: 1526-632X.

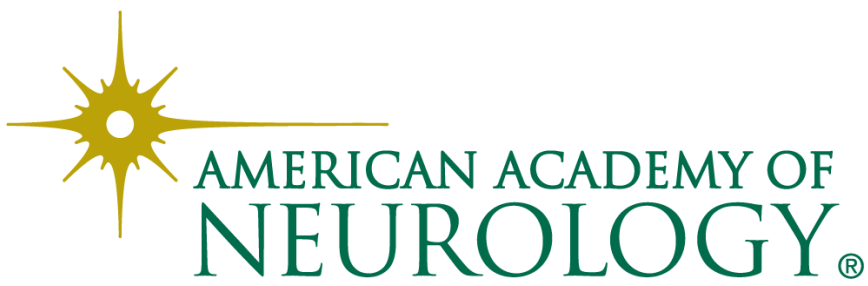

